\title{
What in the world is Public Relations?
}

\section{Tom Watson}

Abstract: This chapter analyses the antecedents, springboards and restraints that have shaped the development of public relations (PR) in more than 70 countries. Based on data from chapters in the preceding five books in the series, it proposes there are three common antecedents of PR activity - early corporate communication, governmental information and propaganda methods and cultural/religious influences. The springboards for PR's growth have been professionalization and education, along with the opening of economies and political plurality. The restraints have been political and economic, such as one-party states and dictatorships and closed economies. PR's historiography is also explored and identifies periodization as the primary method. Future research should move on from the current discovery stage into more analytical and critical processes.

Keywords: antecedents; historiography, history of public relations; PR, restraints; springboards;

One of the purposes of this series was to encourage scholarship that, from greatly varying national and cultural perspectives, brought new perspectives to our understanding of the development of public relations. In the five books that focus on 'national perspectives', insights and data have been gathered from 73 countries in all continents and regions outside North America, which is very well recorded and interpreted.

Specifically, the series set out to identify 'contextualized emergent theoretical frameworks and historiography that value differences, rather than attempting to 'test' an established theoretical framework or historiographic approach’ (Watson 2014/15, p. x). This is a 
relatively new field of historical research and, in many countries, is still at a stage of discovery and of the first production of historical research and written outputs. So it is lacking theoretical and historiographical frameworks, and of scholars who have built a corpus of research that can be debated and reinterpreted. However, this rawness can be an advantage in that scholars ask fundamental questions, discover connections and linkages, create new oral and text archives and start writing their own historiographical approaches.

Two examples of unexpected linkages that were exposed in the series but have yet to be explored are (1) the role of the U.S. Government in promoting public relations in Europe in the immediate post-World War II era of the Marshall Plan (European Recovery Plan). Examples from Greece, Italy, France, and Belgium show that PR was promoted as an element in democratization; there is a similar example in Eastern Europe after 1989/91 when Berlin Wall fell and the Soviet bloc collapsed. Both periods need greater exploration but the ‘democratization’ factor only became evident when all these histories are analyzed together.

There was a similar instance of an individual PR adviser, Eric Carlson, who first primed public relations' development in Brazil in 1953 (Nassar, de Farias and Furlanetto, in Watson, 2014d) and then appeared in Costa Rica the following year (Fallas, in Watson 2014d). Carlson is described as a professor from the U.S. and it would be interesting to know more about him - who was he, which organization(s) sponsored his visits, what were their objectives, how was PR presented and defined at that time? There were other academics and trainers from the U.S. who appeared in Latin American countries in the 1950s and helped shape PR's development but there is only cursory information about them and none appear to have contributed to PR scholarship or its body of knowledge.

In Africa, chapters from Kenya, Uganda, Botswana, Zambia and Zimbabwe and Nigeria reflected on the colonial inheritance of British governmental information dissemination 
processes and how these continued to influence these countries for a decade or two after independence. This colonial connection is also evidenced in the chapter on the United Kingdom. It is also confirmation that governmental communication was probably more sophisticated and engaged with 'best practice' concepts than scholars of propaganda and public administration history have previously been prepared to allow for.

The series has also brought forward forms and practices of public relations that have evolved very differently from western models or which started with these 'international' types of PR practice but then modified them. The prime examples of the culturally-developed public relations are Buddhist (Thailand), Confucian (China, Taiwan and Vietnam), Islamic (Egypt, Kingdom of Saudi Arabia, and the Arab Gulf nations). Although 'international PR' is available for multi-national corporations and those who seek uniformity of corporate and brand expression, there are parallel and confident models of culturally-flavoured PR that have emerged over the past century (or more in the case of Thailand).

To further understand the variegated history of public relations, four themes will be explored in this chapter:

- Antecedents - Proto-PR (Watson, 2013) and early influences that shaped public relations practice.

- Springboards - The factors such as economic, political and social conditions, events, and personalities that enabled PR to advance into a distinct field

- Restraints - Cultural, economic, political and social aspects that delayed the emergence of PR as a fully-fledged practice

- Historiography - The interpretation of the history of public relations by scholars

The chapter will conclude with suggestions for future research. 
The data for the discussion that follows has been drawn wholly from the preceding five books in the National Perspectives on the Development of Public Relations: Other Voices series. They are referenced as Watson 2014a (Asian), 2014b (Eastern European), 2014c (Middle Eastern and African), 2014d (Latin American and Caribbean) and 2015 (Western European). As this is the most extensive collection of scholarly writing on the history of PR outside North America, this author contends that it is a robust basis for analysis. Where references are drawn from specific chapters, the authors are identified. Otherwise, readers should make a general presumption that analysis and commentary is based on the book series.

To prepare this thematic analysis, national histories have been scrutinized to identify key stages of development of public relations in a linear manner in order to identify the baseline influences and areas of practice that followed. Here are three culturally-different examples:

Hungary: [Soviet era] Propaganda $\rightarrow$ "Economic propaganda" $\rightarrow$ [1990/91] Local PR Agencies and Professional Association $\rightarrow$ Education

This indicates that Soviet era propaganda and later 'economic propaganda' (a euphemism for promotional publicity) were the Antecedents, with the emergence after 1990/91 of local PR agencies and the early formation of a professional association being the Springboards for the formation of an expanding practice. This led to the creation of education and training which supported the institutionalization and professionalization of the field.

Thailand: Cultural antecedents (Buddhist; monarchial) $\rightarrow$ Governmental (informational) $\rightarrow$ Corporate/Governmental (state agencies) $\rightarrow$ Corporate (US models in 1960s and 1970s) $\rightarrow$ Less developed Agency sector $\rightarrow$ Education $\rightarrow$ Corporate (local models) / MNC Corporate (western models). 
For Thailand, the Antecedents for public relations are much earlier than Hungary and are embedded in culture, religion and society through Buddhist practices and reverence for the monarchy. Public relations in a governmental informational form (Antecedent) can be traced to the latter part of the $19^{\text {th }}$ century and was confirmed in the 1930 s with the formation of a central governmental public relations and advertising organization. Subsequently, the growth (Springboards) of public relations has been gradual, mainly from corporate and governmental influences. Only in the past 20 years, has an agency sector formed and international models of public relations been introduced by multi-national corporations (MNC) and international agency networks.

Turkey: [1950s] Sub-category of Public Administration $\rightarrow$ [1960s] Governmental $\rightarrow$ Education $\rightarrow$ Corporate $\rightarrow$ [1970s] Agencies $\rightarrow$ [1990s] International agencies $\rightarrow$ Municipal / NGOs.

In Turkey, which has a vibrant public relations sector, the Antecedents, like Thailand, were in government but with PR considered as an element of public administration practice rather than having evolved from journalism and advertising, as found in other countries. The Springboard for growth was PR's emergence within government as a separate communication practice for which training and education was required. Subsequently, the field has both expanded and contracted, largely due to governmental attitudes and respect for communication with the populus.

\section{Antecedents}

Asia: PR began from three separate sources: Colonial governments, cultural influences and governmental communication. Of the 11 nations reviewed in this chapter, only Thailand was never colonised or significantly occupied. Thus the impact of British, Dutch, French, Spanish and US colonial administrations can be found in Australia, India, Indonesia, Malaysia, New 
Zealand, the Philippines and Vietnam. These administrations developed informational systems, assisted the formation of newspapers and performed propaganda duties in wartime and when countering independence movements (India, Indonesia, Malaysia, and the Philippines). The French and U.S. influences in Vietnam were, however, negated by the Communist party control from the mid-1970s onwards (Van, in Watson 2014a). As indicated above, Buddhism was a formative antecedent in Thailand, while Confucianism shaped PR in China, Taiwan and Vietnam. In Japan, post-World War II U.S. occupation government helped create a public relations sector, although there were earlier propagandist practices.

Eastern Europe: The interpretation of the history of PR has two camps: those countries (Bulgaria, Poland, Russia and Ukraine) for which it is a late $20^{\text {th }}$ century phenomena that followed the breakup of the Soviet bloc and subsequent democratization; and those (Croatia, Czech Republic, Hungary, Romania and Slovenia) for which there was proto-PR during the $20^{\text {th }}$ century and, in the case of Romania, back to the $19^{\text {th }}$ century. For the first group, PR emerged as a U.S. agency model, primarily engaged in political communications, and then the promotion of branded consumer products. In the second group, there were strong indications of PR in commercial and governmental applications before the Soviet era and, in Croatia, Czech Republic, Hungary and Slovenia, during that period when it was applied to support marketing of exports.

Middle East and Africa: As in Asia, there are three antecedents - colonial (Botswana, Zambia, Zimbabwe, Kenya, Nigeria, Uganda), cultural (Arab States of the Gulf, Kingdom of Saudi Arabia) and governmental (Egypt, Israel, South Africa, Turkey). The colonial influences were all British and expressed as informational processes from governments. It is notable that these processes have persisted. In the Arab world, the influence of Islam and tribal connections set the basis for indigenous PR, although a parallel model of U.S.-style promotional activity evolved in the latter part of the $20^{\text {th }}$ century. Governmental 
communication, sometimes political and propagandist, was linked to public administration practices as exemplified in the Turkish model discussed earlier.

Latin America and Caribbean: This regional grouping had corporate (Argentina, Brazil, Central America, Colombia, Mexico) and governmental (British Caribbean, Peru) beginnings of PR. The British Caribbean practices across three countries (Barbados, Jamaica, Trinidad \& Tobago) evolved from colonial governments, although there is little record, other than in Argentina, of Portuguese or Spanish colonial influence on Antecedents.

Western Europe: Other than in Germany and the U.K., PR is mostly positioned as a postWorld War II phenomenon. In the Netherlands, the voorlichting tradition can be traced to the $18^{\text {th }}$ century Enlightenment and there is evidence of pre-war organised propaganda in Italy but Germany with a strong corporate and governmental communications culture from the second half of the $19^{\text {th }}$ century onwards and the U.K. with colonial and national governmental communications in the first half of the $20^{\text {th }}$ century can be positioned in the pre-World War II period, In the aftermath of 1945, corporate (Belgium, Denmark, France, Greece, Italy, Netherlands,) and governmental (Austria, Finland, Germany, Greece, Italy, Netherlands, Spain, Sweden, U.K.) communication processes and operations set the base on which PR was to develop, followed soon after by the formation of professional associations. In some nations, notably, Greece, Italy and the Netherlands there was almost simultaneous evolution of corporate and governmental practices. In most of Western Europe, other than Spain, the influence of U.S. approaches to organizational and promotional communication can be identified and will be discussed later.

In summary, there were three common Antecedents of public relations practices: early corporate communication; governmental (often colonial) information and propaganda methods; and cultural influences drawn from dominant religions (Buddhism, Confucianism 
and Islam). The timescale varies widely from the formation of German practices in the mid to late $19^{\text {th }}$ century to the final decade of the last century in Eastern Europe, following the fall of the Berlin Wall and the break-up of the Soviet bloc.

\section{Springboards}

Asia: Across most of Asia and Australasia, the evolution and rapid growth of agency PR in the 1970s and 1980s was part of a world-wide expansion of the field which was characterised by the formation of professional associations, the commencement of organized training and education and expansion of employment in the field. In this region (and others discussed later), the 'agency boom' was an outcome of the Springboards of PR's growth. The time scale varied: For example, Australia’s development had a more than 20-year gap between the formation of a professional body (the Public Relations Institute of Australia) and growth of corporate PR in the 1950s, and the start of university-level degree studies in the 1970s. This was followed by rapid growth of the agency sector. However other countries (Indonesia, Malaysia, Singapore, Taiwan) focused on governmental communications to foster nationbuilding with formation of professional bodies, education and the agency sector following later. In China, India and Thailand, growth of the field came from governmental PR aided by the loosening of economic controls, notably in India.

Eastern Europe: Unlike Asia, with its varied speeds of growth of the field, political and economic change concentrated in a three-year period from 1989 to 1991 gave strong impetus to PR practice in all forms (agency, corporate and government). This could be considered as a 'democratic dividend' that led to rapid institutionalization, professionalization and expansion of education. Although Croatia and Slovenia had been outside the Soviet bloc in Yugoslavia, their PR sectors had limited opportunity to expand and they also benefited from the changes at this time, although soon affected by the Balkan conflict of the early to mid-1990s. 
Middle East and Africa: In former colonial nations, PR followed a similar track of postcolonial governmental communication supporting nation-building inside and outside the country, followed by corporate communication undertaken by major exporters, professionalization through formation of associations based on and with links to the UK's (then) Institute of Public Relations (IPR), development of training and education and then emergence of the agency sector, largely linked to major corporate clients. There was a similar sequence in South Africa. However, the sequence in the Arab Gulf and Kingdom of Saudi Arabia was that the expansion of the oil industry fostered corporate PR which was followed by governmental expansion and the formation of advertising agencies which set up PR offshoots. Later came professionalization, education and agency growth. In Egypt and Israel, governmental PR was followed by formation of professional bodies and then growth of education and the agency sector. In the Arab world, two models of PR practice evolved local/indigenous and international - for different markets and clients. The local/indigenous model retains aspects of hospitality based on long-standing cultural communication.

Latin America: Although this region was less affected by World War II, it was not until the 1950s that PR began its growth. It is notable that Latin America, like Western Europe, was quick to professionalize. From the late 1950s onwards, practitioners met regionally and then linked with the International Public Relations Association (IPRA) and the Public Relations Society of America (PRSA). As noted in the Introduction to the volume on Latin America and the Caribbean, "the theoretical and practice base of PR did not, however come from the former colonial powers but from the United States which, according to its Monroe Doctrine, considers Latin America to be in its sphere of influence” (Watson, 2014d, p. 2). Thus one of the Springboards for growth was the formation of professional associations at national and regional level. This paralleled growth of corporate communications practice and preceded the development of education and, later, formation of agencies. Only Mexico had a well- 
developed agency sector by mid-20 ${ }^{\text {th }}$ century. The British Caribbean followed a post-colonial model of governmental PR growing ahead of developments in corporate communication. This was followed by professional associations, similar to the former African colonies, linked to the London-based IPR, and then education. Agency growth has always been on a small scale.

Western Europe: As foreshadowed in the discussion of Antecedents, growth of PR came after World War II, and was fostered by U.S. influence in several countries. This was delivered through the United States Information Service (USIS) operations which employed local practitioners and through visits to the U.S. that were funded through the Marshall Plan (the European Recovery Program). The initial Springboards came from governmental activity and, as economies recovered, corporate PR. Most European countries also formed professional associations at this time (Italy had three at once in the 1950s), with the International Public Relations Association (IPRA) coming into being in 1955, largely as a European initiative although the PRSA was involved. In the UK, which like Germany had pre-war governmental and corporate PR structures, the National Association of Local Government Officers (NALGO) trade union played a central role in the formation of the IPR in order that its PR practitioner members would be professionalized and the activities given legitimacy (L’Etang, in Watson, 2015). Most countries, however, formed their associations from practitioner communities who sought professional status and employer recognition. Outside the Marshall Plan nations, Spain and Portugal struggled to develop their PR sectors until the 1970s as they were still under the rule of dictators. In Spain, professional bodies were gradually formed in the 1960s as controls on the formation of associations were eased. The agency sector in many countries started developing in the 1950s but did not accelerate growth for 20 years. In that decade, the first of the U.S. agency networks started operating in Europe, following North American clients into revived markets. 
In summary, a general pattern of the Springboards for PR development is proposed as:

\section{Government $\rightarrow$ Corporate $\rightarrow$ Professional Association $\rightarrow$ Education $\rightarrow$ Agencies}

However, like all attempts at a general rule, there are significant exceptions according to culture. In some cases, such as post-war Western Europe and post-Berlin Wall Eastern Europe, the expansion of Government and Corporate PR while not utterly simultaneous often occurred in a similar five-year period. In most countries, professional associations preceded the introduction of specialist PR education and training, as these bodies sought education as a key element of their professionalization and legitimization. These associations were persistent advocates and were supported by IPRA and PRSA in the preparation of sample educational curricula.

As commented upon in the section on Asia's Springboards, the growth of the agency sector was an outcome of the general growth of the sector, professionalization and education. It was to prosper from the 1970s onwards, once the ground work had been done to establish the field in many countries. Other observations are the influence of British governmental communications practice in many former colonies and of the U.S. in Eastern and Western Europe and in Latin America.

\section{$\underline{\text { Restraints }}$}

Asia: PR's growth in this region has been limited and slowed at various time across the region. In China, it is only in the past 15 years that agency PR, the most commerciallysensitive form of practice has thrived. As in neighbouring Vietnam, the one-party state and state corporatism had limited promotional activity for several decades in favour of propaganda and controlled media. India, post 1947, maintained a controlled statist economy for three decades before gradually easy restraints after which both corporate and agency PR 
expanded. However, the legacy was that its practice model was long based on media relations and publicity tactics, with little consideration of strategic communications approaches. Postindependence, Indonesia, Malaysia and Singapore focused on nation-building and media controls which limited growth of non-governmental PR but as these economies opened up and greater media freedom was allowed, the field began to expand. Singapore is now the main Asian regional hub for corporate and agency PR and media/creative industries. PR in the Philippines was restrained and, to some extent, abused in the Marcos era but expanded once those controls were released.

Eastern Europe: From the end of World War II to the early 1990s, PR was heavily controlled or non-existent in much of the Soviet bloc. Its growth only began when the previous regimes were replaced in democratic elections. From the 1990s to the mid-2000s, was a period of great expansion of all forms of PR. In the early period, as reported in the Russia chapter and other countries, political PR and campaigns to reinforce new democratic structures and then EU accession funded growth. As suggested earlier, PR's growth has been a result of the 'democratic dividend'.

Middle East and Africa: Quite diverse restraints have applied to PR in this region. South African PR operated under the apartheid era controls of media and personal liberties from the 1950s to the early 1990s. Although there were some characteristics of normal professional development such as industry organisations and higher education, its growth and reputation were very troubled. PR in Israel was restrained from 1948 for 30 years by a collectivist mentality that limited criticism of government. This was reinforced by media controls. When more pluralist views arose, the media (and PR) began to expand. So much so that the past two decades are considered to be a 'golden age' for PR (Magen, in Watson, 2014c, p. 53). The progress of PR in Turkey has often been related to government's attitude and respect for it. Similarly, Egyptian practice has been affected by governmental controls on media and 
political turbulence. A once-thriving PR sector in Zimbabwe has been virtually wiped out since 2000 by government policies and the collapse of the economy.

Latin America: In the nations of Central America (Panama, Costa Rica, Nicaragua, Guatemala, El Salvador and Honduras), a correlation between democracy and the growth of PR has been evidenced (Fallas, in Watson 2014d). It prospers in nations with open economies and political pluralism, but is weak in dictatorships and one-party states. This correlation was also found in Peru where statism for much of the second half of the last century ossified PR, as well as the media and other modes of communication, until the 1990s when the national Constitution changed (Sánchez de Walther, in Watson, 2014d). Argentina and Brazil both had periods of military government which limited media and personal expression that, in turn, restrained PR. Once these periods had passed, and the economies were opened to external investment, PR grew in all forms, as did education and training.

Western Europe: The development of Spanish PR was arrested during the Francoist era which ran from 1939 to the mid-1970s. However, practitioners found that they could develop near-normal campaigns by carefully avoiding topics and attitudes that could cause problems. Even so, it proved difficult to develop professional bodies because the regime has laws against the formation of association. From the end of the Franco period, PR accelerated its growth to similar levels of other Western European nations. Practitioners in Greece, which had a military dictatorship from 1967 to 1974, continued to grow their businesses and the industry (Theofilou, in Watson, 2015) by avoiding controversy. Tourism and the attraction of inward investment were important campaign themes that aided PR's development during both these restrictive regimes. Greek practitioners had another problem: they were unable to separate PR from advertising. Latterly, their professional association has been subsumed into an advertising sector-dominated organisation. 
When the Restraints upon PR are considered, there is an observation that is more generalizable that was possible for the Springboards. It is that PR thrives in democratic environments in which there is a relatively open economy. This can be applied to agency, corporate and governmental modes, although there is insufficient historical evidence that this viewpoint could be extended to non-profit or activist PR. It also appears that, while tacticallyled publicity and media relations are the most common forms of practice, propaganda is not fostered by its association with promotional and persuasional forms of communication.

\section{Historiography}

The analysis of historiographic approaches has been undertaken using the same regions as the discussion of the other aspects. Periodization, not surprisingly, was the most common approach whether as timeline narratives or date-based stages of development.

Asia: Bentele’s functional-integrative structural model (Bentele, 2010) was adapted to Thai historical circumstances when advancing four strata of public relations evolution (Tantivejakul, in Watson 2014a). Periodization as 'period', 'phase' or 'stage' was applied to the histories of China, India, Indonesia and Taiwan. Other national histories were expressed as time- and date-based narratives. The China chapter took the longest view by placing the antecedents of PR-like activity in ancient times; whereas the histories of former colonies such as Indonesia, Malaysia, Singapore, Taiwan [a Japanese colony], and Vietnam commenced at the eve of World War II or soon after 1945 when independence movements arose against the colonial powers.

Eastern Europe: Historiographic interpretation came in two discrete sets: those which identified antecedents and those which vehemently placed the arrival of PR as a post-Berlin Wall and democratization phenomenon, with no backward consideration of promotional activity in the Soviet era. Timelines were adopted in Czech Republic, Hungary, Poland, 
Romania and Slovenia. Thematic approaches that emphasized institutionalization followed by education and training were used for other countries. Only the Poland chapter had the specific historiographic model of 'transitional public relations' (Lawniczak 2001, 2005) utilized to interpret the evolution of PR.

Middle East and Africa: There was little consistency of interpretation across the very diverse group of countries. Three chapters - Egypt, Israel and Turkey - used periodization. Thematic analysis was applied in another three - Botswana, Zambia and Zimbabwe, Nigeria, and Uganda - possibly indicating the commonality of British colonial public administration approaches to information dissemination. However, Raaz and Wehmeier’s (2011) 'fact-event oriented, periodizing and theorizing' was used for Israel and was the only instance of a specific historiographic model.

Latin America and Caribbean: Most chapters have used timelines as analytic processes and to shape narratives, while authors noted that there was little resource in the form of archives and previous public research on which scholarly approaches could be formed. The Peru chapter used a bibliographic approach through which a half-century of PR texts were analyzed to build insights into the formation of PR in the country and create a narrative through which institutionalization could be scrutinized. For Argentina, the country's economic growth and industrialization was an allegory for a century of PR progression as a field of organizational communication.

Western Europe: Periodization was applied to several chapters as a route to explore themes and influences: the number of periods ranged from three for Austria, focused wholly on the post-war period to seven in Germany, where analysis starts with pre-history or proto-PR influences. Bentele’s functional-integrative structural model (Bentele, 2010) is the most fullydeveloped model, as noted for Thailand earlier, it can be adapted for different national 
histories. Otherwise, the region’s histories were expressed a narrative timelines, with sideward looks at influences (e.g. postwar US programmes) and the subsequent evolution of national approaches.

\section{Future research}

In collating the histories of PR from 73 countries in 47 chapters in five books, it is obvious that the jam has been spread rather thinly. For many countries, as noted earlier, these chapters were the first or an early effort to record and interpret the introduction of public relations as a defined practice. For example, the history for Central America (Fallas, in Watson 2014d) covered six countries most of which had not collated any form of history in text, audio or visual archives. It was a major effort by Carmen Mayela Fallas from Costa Rica to gather material, with assistance from academic and professional colleagues, into this chapter. They now have a basic history, at discovery level, which can be built upon, analysed and critiqued. And they were not alone in doing basic research.

The major research challenge for PR historians is to gather oral histories, organizational records, personal archives and artefacts of all types before the early generations of practitioners fade away. The creation of archives is an important step for research to be conducted in ways that challenges the verities often retailed by those with personal legends and progressivist myths to create and perpetuate. The example of Edwards Bernays' selfaggrandisement has long over-balanced the understanding of PR's development in the U.S., where the ‘Great Man’ myth has only recently been challenged (Watson, 2014e).

Research also needs to challenge the application of western models of PR as the sole or major model practice. As I noted in a Public Relations Review commentary: 
By applying a framework from a Western corporatist culture to post-Communist Eastern Europe or communitarian Southeast Asia, a dangerous short cut has been taken. More encouragement must be given to nascent historians to go to archives, gather interviews and data, and develop historical analyses (Watson, 2014e, p. 875)

Although this commentary was published during the period in which the National Perspectives on the Development of Public Relations: Other Voices series has been written, the vast majority of authors have written chapters based on the evolution of PR in their countries without comparison to 'Western corporatist' models. PR has thus been portrayed as a rich tapestry of models and concepts, which (and mixing metaphors from jam to carpets) covers the basis of future research.

The series has also established a larger community of PR historians world-wide. Although some have met personally through attendance at the annual International History of Public Relations Conference, there are a similar number who are joining this new and growing group of scholars. In addition to fostering national histories, I hope that 'cooperation between PR historians must grow ... with comparative studies across nations, cultures and organizations' (Watson, 2014e, p. 876). As the editor reading all the chapters in five preceding books, there appear to be numerous cross-cultural and transnational links. For example, who was Eric Carlson and who sent him to Brazil and Costa Rica in the early 1950s? How did the court of King Chulalongkorn of Thailand conduct a media relations campaign in Europe at the end of the $19^{\text {th }}$ century and what impact did it have in Europe and on Thailand? How did the USIS, Marshall Plan resources and the Occupying Forces conceive PR and then promote it so effectively in post-World War II Europe and Japan? This list could go on and on. It shows the intersection of public relations with culture, economics, politics and society, and with media and other methods of promotional communication. There is so much to discover, analyze and critique. 


\section{References}

Bentele, G. (2010) 'PR-historiography, a functional-integrative strata model and periods of German PR history' [Abstract], Proceedings of the First International History of Public Relations Conference, Bournemouth University, UK, 8-9 July, 2010.

Fallas, C.M. (2014) 'Central America', in T. Watson (ed) Latin American Perspectives on the Development of Public Relations: Other Voices (Basingstoke: Palgrave Macmillan). Ławniczak, R. (ed) (2001) Public Relations Contribution to Transition in Central and Eastern Europe. Research and Practice (Poznan: Printer).

Ławniczak, R. (ed) (2005) Introducing Market Economy Institutions and Instruments: The Role of Public Relations in Transition Economies (Poznan: Piar.pl).

L’Etang, J. (2014) ‘United Kingdom’, in T. Watson (ed) Western European Perspectives on the Development of Public Relations: Other Voices (Basingstoke: Palgrave Macmillan). Magen, C. (2014) 'Israel', in T. Watson (ed) Middle Eastern and African Perspectives on the Development of Public Relations: Other Voices (Basingstoke: Palgrave Macmillan).

Nassar, P., de Farias, L-A., and Furlanetto, M. (2014) 'Brazil', in T. Watson (ed) Latin American Perspectives on the Development of Public Relations: Other Voices (Basingstoke: Palgrave Macmillan).

Raaz, O., and Wehmeier, S. (2011) 'Histories of Public Relations: Comparing the Historiography of British, German and US Public Relations’, Journal of Communication Management, 15(3), 256-275.

Rodriguez-Salcedo, N. (2015) 'Spain’ in T. Watson (ed) Western European Perspectives on the Development of Public Relations: Other Voices (Basingstoke: Palgrave Macmillan).

Sanchez de Walther, A. (2014) 'Peru', in T. Watson (ed) Latin American Perspectives on the Development of Public Relations: Other Voices (Basingstoke: Palgrave Macmillan). 
Tantivejakul, N. (2014) 'Thailand', in T. Watson (ed) Western European Perspectives on the Development of Public Relations: Other Voices (Basingstoke: Palgrave Macmillan). Theofilou, A. (2015) 'Greece', in T. Watson (ed) Western European Perspectives on the Development of Public Relations: Other Voices (Basingstoke: Palgrave Macmillan).

Van, L. T. H. (2014) 'Vietnam', in T. Watson (ed) (2014a) Asian Perspectives on the Development of Public Relations: Other Voices (Basingstoke: Palgrave Macmillan).

Watson, T. (2013) ‘Keynote Speech to the International History of Public Relations Conference 2013', https://microsites.bournemouth.ac.uk/historyofpr/files/2010/11/Tom-Watson-IHPRC2013-Keynote-Address4.pdf, date accessed 06 March 2015.

Watson, T. (ed) (2014a) Asian Perspectives on the Development of Public Relations: Other Voices (Basingstoke: Palgrave Macmillan).

Watson, T. (ed) (2014b) Eastern European Perspectives on the Development of Public Relations: Other Voices (Basingstoke: Palgrave Macmillan).

Watson, T. (ed) (2014c) Middle Eastern and African Perspectives on the Development of Public Relations: Other Voices (Basingstoke: Palgrave Macmillan).

Watson, T. (ed) (2014d) Latin American and Caribbean Perspectives on the Development of Public Relations: Other Voices (Basingstoke: Palgrave Macmillan).

Watson, T. (2014e) 'Let’s get dangerous - a review of current scholarship in public relations history’, Public Relations Review 40(5), 874-877.

Watson, T. (ed) (2015) Western European Perspectives on the Development of Public Relations: Other Voices (Basingstoke: Palgrave Macmillan). 